\title{
EXPOGRAFIAS ITALIANAS DO PÓS-GUERRA, O MASP NA RUA 7 DE ABRIL E NA AVENIDA PAULISTA
}

\author{
Alexander Gaiotto Miyoshi \\ Arquiteto (FAU-USP, 1999), mestre em história da arte (IFCH-UNICAMP, \\ 2007) e doutorando em história da arte (IFCH-UNICAMP)
}

Nas primeiras décadas do século XX a expografia foi tema de intenso debate. A densificação de pinturas nas paredes dos museus passou a ser vista por muitos como uma incômoda congestão ${ }^{1}$. $\mathrm{Na}$ Itália, o acúmulo das obras em salas expositivas estimulou slogans proclamando a morte dos museus $^{2}$. Em diversas partes da Europa reorganizaram-se as mostras de arte, com o objetivo de não prejudicar a qualidade da apresentação e a percepção dos quadros e esculturas.

Uma das respostas a esse problema foi proceder à bipartição do acervo, experimentada com sucesso por Wilhelm von Bode, em Berlim. Tratava-se de uma redução das coleções expostas, selecionadas para mostra ao grande público, enquanto as demais obras seriam guardadas nas reservas técnicas, acessíveis a experts e estudiosos ${ }^{3}$. A difusão do procedimento foi ampla. Ainda na Alemanha, a Galeria de Dresden foi reformada no final dos anos de 1920 constituindo um exemplo da "depuração" das paredes, das transformações museais e das discussões em torno da solução:

... Hans Posse, diretor da Galeria entre 1910 e 1942, criticou a iluminação e o pé-direito das salas, as decorações e os revestimentos das paredes. Como resultado, as abóbadas foram reduzidas à forma atual e o vidro do teto foi rebaixado. Posse descreveu a velha aparência decorativa das salas como "horrível depósito sobre as paredes", enquanto [o diretor precedente, Karl] Woermann, em suas memórias de 1924, em extrema oposição, alertou contra o "gosto neurastênico de um esteta", e acrescentou: "Mesmo a colocação de duas pinturas uma sobre a outra encontrou freqüente desaprovação. De fato, logo se tornaria regra reservar uma área especial da parede para quase apenas uma pintura" ${ }^{4}$.

\footnotetext{
${ }^{1}$ HUBER, Antonella. Il Museo italiano. La trasformazione di spazi storici in spazi expositivi. Attualitá dell'esperienza museografica degli anni '50. Milão: Edizioni Lybra Immagine, 1997, p. 44.

2 Id. Ibid. p. 53.

${ }^{3}$ Id. Ibid. p. 44.

4 “... Hans Posse, the Gallery's director from 1910 to 1942, criticized the lightning and room height, wall decorations and wall coverings. As a result, the vaulting in the halls was reduced to its present form, and the glass ceiling was lowered. Posse described the old decorative appearance of the halls as "ugly depot-like filling of the walls", while Woermann, in his memoirs of 1924, warned against going to the other extreme of the "neurasthenic taste of an aesthete". He added: "The hanging of even two pictures one above the other often met with disapproval. Indeed, it soon became the norm to demand a special section of wall for almost every picture'". MARX, Harald. WEBER, Gregor J. M. Staatliche
} 
O princípio da bipartição do acervo incorporou-se a outros debates; um deles sobre a mostra didática e temporária, modalidade de exposição cada vez mais celebrada; o outro sobre a construção de novos edifícios $^{5}$, criados não apenas para oferecer salas de exposição e reserva técnica adequadas, como também para receber e estimular melhor o público. Conclamaram-se os museus para que fossem mais "úteis e interessantes" ", o que exigia "modificações nos modos, padrões e objetivos das exposições". Os trabalhos pedagógicos e as monitorias deveriam atender pessoas de todas as idades e padrões culturais ${ }^{7}$. A participação do museu na educação formal do público tornou-se palavra de ordem. Para tanto, se não fosse possível construir novos edifícios, que se fizessem reformas e adaptações nos velhos edifícios.

$\mathrm{Na}$ Itália, reformar e adaptar edifícios para o uso de museus foi uma solução constante em quase todo o século $\mathrm{XX}^{8}$. Os fatores particulares da arte, das coleções e do patrimônio italianos conduziram ao desenvolvimento de uma arquitetura interna, atenta às particularidades das obras de arte e edifícios históricos. Embora tal prática de adaptação de prédios ao uso museal não tenha se restringido à Itália (ocorreu também com o MoMA de Nova Iorque e com o primeiro MASP, da rua 7 de abril, entre outros), foi lá que o "museu interno" 9 obteve resultados extremamente diversificados e surpreendentes.

Segundo Paolo Morello10, há uma idéia geral sobre a "museografia do pós-guerra" na Itália, que a rica tradição historiográfica italiana transmite: o fim da Segunda Guerra Mundial contribuiu para uma revolução museográfica, cujas condições de tabula rasa (ou "grau zero")

Kunstsammlungen Dresden. The Old Masters Picture Gallery (catálogo reduzido da Galeria de Pintura dos Velhos Mestres de Dresden, versão em inglês). Munique/Berlim: Deutscher Kunstverlag, 2001, p. 7.

5 HUBER, Antonella. Op. cit. p. 44.

6 MORLEY, Grace. "Les Musées et l’Unesco/Museums and Unesco". Museum. Vol 2. Paris: Unesco, 1949 (reimpressão 1973), pp. 19-20, apud SCHINCARIOL, Zuleica. Através do espaço do acervo: o Masp na 7 de abril. São Paulo: FAU-USP, 2000 (dissertação de mestrado), p. 14.

7 Id. Ibid.

8 Pelo menos até 1997, 60\% dos edifícios para museus italianos eram anteriores ao século XIX, sendo que $50 \%$ das instituições museais foram fundadas depois de 1945 . Havia na Itália " 28 edifícios-sedes de museus anteriores ao século XII, 483 construídos entre os séculos XII e XVI, 544 entre o XVII e o XIX". BROSIO G. SANTAGATA. W. "Dal Rapporto sull'economia del sistema de arte, i Beni Culturali e i Musei in Italia”. Pesquisa publicada em Il Giornale dell'Arte. 1991, 97. Apud HUBER. Op. cit. p. 14.

9 GREGOTTI, V. “Il territorio museo". Casabella, 574, dezembro de 1990, p. 2. Apud Id. Ibid. p. 14.

${ }^{10}$ MORELLO, Paolo. "La museografia. Opere e modelli storiografici". DAL CO, Francesco. Storia dell'architettura italiana - il secondo novecento. Milão: Electa, 1997, p. 392. 
permitiram renovar a "museografia cinzenta e ainda oitocentista do regime fascista". A "estrutura recorrente" seria: "um prólogo em negativo" seguido por uma "cisão catastrófica ... e uma refundação, sem memória alguma do passado". As intervenções dos anos 40 aos 60 surgem como os grandes exemplares da museografia italiana, sobretudo realizadas pelos arquitetos Franco Albini e Carlo Scarpa.

Marco Mulazzani lembra que a experiência italiana foi possível graças às feiras, exibições e mostras temporárias ocorridas no entre-guerras, ressaltando que, embora as "experiências estéticas" nos dois tipos de exposição tenham "componentes comuns - as obras e o público -, o que distingue os significados, os valores e as formas de um museu e uma mostra são as diferentes relações entre os componentes específicos, tais como espaço e tempo, com respeito aos conceitos de fixo ou móvel, mutável ou imutável, temporário ou permanente" 11.

No entre-guerras, a liberdade dos projetos para as mostras temporárias foi maior que a das exposições permanentes dos museus. Apesar da crescente difusão dos princípios museológicos educativos, a Itália não se abriu a eles facilmente. Assim, a exposição temporária foi o terreno fértil às experimentações expositivas. Mas as experiências só eram viáveis quando não envolviam coleções antigas de pintura e escultura: foi o que ocorreu com as propostas de Edoardo Persico e Marcello Nizzolli para a Sala da Medalha de Ouro, a de Giuseppe Pagano para a Sala de Ícaro, do escultor Marcello Mascherini, ambas em 1934 na mostra da Aeronáutica no Palazzo d'Arte em Milão, e para a mostra de Ourivesaria Antiga, de Franco Albini, em 1936, para a VI Trienalle de Milão.

Essas mostras pertencem, em alguma medida, ao mesmo universo do museu projetado por Henry van de Velde entre 1920-26, o KröllerMüllers $^{12}$, e os projetos experimentais de Alexander Dorner no Landesmuseum de Hannover, entre 1923-36 - sobretudo o "gabinete abstrato", realizado com El Lisickij em 1925, e o projeto para a "sala do nosso tempo", realizado com Moholy Nagy em 192813. O último, porém,

\footnotetext{
${ }^{11}$ MULAZZANI, Marco. "Lo spazio interno come spazio architetatto". In HUBER, Antonella. Op. cit. p. 59.

12 Id. Ibid. pp. 47-49.

13 Dorner estimulou particularmente o debate museal, colocando o homem como personagem central do museu: a um só tempo criador (artista) e espectador (fruidor). Seus experimentos são considerados os primeiros a integrar "a participação ativa, física e espiritual do visitante”. Id. Ibid. pp. 51-52.
} 
jamais foi realizado e o primeiro foi destruído pelos nazistas, em 1936, como "arte judaico-bolchevique degenerada" 14.

Quanto às experiências italianas com obras de arte antiga no entreguerras, algumas reformas foram realizadas nas salas de pintura e escultura do museu cívico de Bolzano (dentro do espírito de "limpeza" e didatismo apregoado pela nova museologia, mas ainda discretas se comparadas aos exemplos citados anteriormente ${ }^{15}$ ), proposta por Giuseppe Pagano, em 193516. A reforma museográfica na Galeria Sabauda, de Torino, proposta por seu diretor, Guglielmo Pacchioni, foi o único caso italiano elogiado por sua modernidade na I Conferência Internacional de Museografia, realizada em Madrid, em 1934, servindo como modelo mesmo no imediato pós-guerra ${ }^{17}$. De resto, quase todas as experiências museográficas envolvendo coleções artísticas geravam grandes polêmicas ${ }^{18}$, como as realizadas em instituições oficiais como a Quadrienal de Roma e a Bienal de Veneza. Ambas empregavam arquitetos, mas ainda assim haveria nelas uma "total falta de envolvimento com respeito às solicitações do mundo das artes figurativas

${ }^{14} \mathrm{~A}$ intenção dessas mostras era "sugerir uma compreensão do passado não só em termos documentais", mas, segundo Dorner, "concretamente "visuais", superando "a rigidez da galeria, a semi-estaticidade do espaço ordenado segundo a época". Assim, buscava "recriar em todas as salas o clima da época e do artista através de sutis alusões": paredes e tetos escuros evocando o interior de igrejas medievais e claras recordando os "volumes limpos do Renascimento"; na sala barroca, veludos; na rococó, "sinfonia de creme, rosa e ouro na sala rococó". Além disso, o uso de inúmeros "aparatos didáticos": auto-falantes e gramofones, em todas as salas "para facilitar a compreensão das obras", projeção "de filmes sobre arte abstrata, sobre arquitetura, sobre todas as formas de arte da visão moderna". Foi particularmente escandalosa a integração "de fotografias com os originais: em 1929 se organiza uma exposição intitulada "Original e fac-símile", que provocou críticas ferozes". MORELLO. Paolo. DAL CO. Francesco. Op. cit, pp. 408-409.

15 Paolo Morello seleciona algumas intervenções italianas que ocorreriam nas décadas de 40 e 50, de certo modo pouco lembradas pela história da arquitetura (pelo menos entre os anos 70 e 90), concentrada nos célebres trabalhos de Scarpa, Albini e BBPR. Morello qualifica-as pela "“"pobreza” essencial e de discreta messa in valore das obras de arte", ao mesmo tempo em que utilizam tecnologias modernas (sobretudo para iluminação natural). São os casos do San Matteo, de Sanpaolesi, de 194549, em Pisa, e o Capodimonte, de Molajoli e de Felice, de 1952-57, em Nápoles. Ambas priorizam a arte mais que a arquitetura (sem prejuízo da arquitetura), com um cuidadoso equilíbrio entre espaço e iluminação natural, de extraordinária sobriedade museográfica. Id. Ibid. p. 413.

${ }^{16}$ MULAZZANI, Marco. Id. Ibid. pp. 59-61.

${ }^{17}$ MAGAGNATO, L. "La mostra di museologia". Comunità no. 53, 1957, pp. 70-72. Id. Ibid. p. 59.

18 Mulazzani cita dois catálogos com registros dessas polêmicas: LOHSE, R. P., Neue Ausstellungen. Nouvelles conceptions de l'exposition. New design in exbibitions. Verlag für Architektur: Erlenbach-Zurique, 1953. POLANO. S. Mostrare. L'allestimento in Italia dagli anni Venti agli anni Ottanta. Edizioni Lybra Immagine: Milão, 1988. Ver também a bem documentada análise de MORELLO. Paolo. La gatta di Apollo: gli architetti e $i$ musei in Itália 1930-1965 (Trabalho final de graduação, contendo, a polêmica ocasionada com a mostra Ourivesaria Antiga, de Albini e Romano em Milão, em 1936, entre outras). MULAZZANI, Marco. Id. Ibid. p. 61. 


\section{na organização das exposições" ${ }^{19}$. Edoardo Persico chegou a criticar não apenas a mostra da Quadrienal, como os próprios críticos:}

Os críticos da segunda Quadrienal ... como de hábito, liquidaram em quatro linhas ao pé do artigo a organização da mostra ... E se não importa que os bronzes patinados de Messina desapareçam sobre os panos verdes, que na sala dos 'abstratistas' houvesse tapeçarias de outra cor, que Casorati ou Severini ficassem mal naquelas paredes ... quando se chega em frente a Rosai, compreende-se, súbito, que a sistematização de suas telas retangulares, altíssimas, é algo mais que um erro de gosto; em uma sala baixa não é apenas um problema de luz que precisava ser resolvido; mas um problema de concordar pintura e ambiente, pintura e arquitetura, como em uma igreja ou em um palácio ${ }^{20}$.

Após o fim da guerra em 1945, ocorreu um levantamento do patrimônio a ser restaurado ${ }^{21}$. $\mathrm{Na}$ medida do possível, os museus bombardeados foram urgentemente reconstruídos. Se os problemas se resumissem a adaptar edifícios antigos, realizavam-se modificações nos ambientes, "redefinindo percursos e abrindo novas portas" 22. Muitas vezes o projeto e a obra não eram confiados a um arquiteto; outras nem mesmo a alguém que não fosse do museu. Os arquitetos intervinham ora com o edifício já reestruturado por outra pessoa (como Albini no Palazzo Bianco e Scarpa no Abatellis), ora o restaurando e intervindo na seqüência (como Ezio de Felice em Capodimonte e Scarpa em Castelvecchio). A maioria dos museus italianos, porém, dispensava os arquitetos ${ }^{23}$, ao contrário do que se passou desde os anos 20 nos demais países da Europa e nos EUA. Segundo

19 PASQUARELLI. S. "La Quadriennale di Roma. Fra tradizione e innovazione”. ROMANELLI. G. "Per mettersi in mostra. La Biennale di Venezia e $\mathrm{i}$ suoi allestitori". Rassegna, $\mathrm{n}^{\circ} .10$ (Allestimenti/Exhibit Design), 1982, pp. 56-61. Id. Ibid. p. 62.

20 "I critici della seconda Quadriennale - scriveva Edoardo Persico nel 1935 - liquedaranno come al solito com quattro righe in fondo all'articolo la sistemazione della mostra". E se, prosegue Persico, "non importa che i bronzi patinati di Messina si cancellino sulle tele verdi, che alla sala degli 'astrattisti' convenissero tappezzerie di un altro colore, che Casorati o Severini si leggano male su queste paretti ... quando se arriva di fronte a Rosai, si capisce di colpo che la sistemazione delle sue tele rettangolari, altissime, è qualcosa di più che un errore di gusto; in una sala bassa non è più un problema di luce che bisognava risolvere; ma il problema di accordare pittura e ambiente, pittura e architettura come in una chiesa o in un palazzo." PERSICO, Edoardo. "Regia della Quadriennale". L'Eco del mondo, 9 de fevereiro de 1935. Id. Ibid. p. 62.

${ }^{21}$ LONGHI. Roberto. "Bilancio di mostre nel dopoguerra". Paragone, $\mathrm{n}^{\circ} .23,1951$, pp. 67-73. Id. Ibid. p. 63.

${ }^{22}$ MORELLO. Paolo. DAL CO. Francesco. Op. cit, pp. 404-405.

${ }^{23}$ Não foi necessário um arquiteto, por exemplo, na preparação do políptico de São Gregório, de Antonello da Messina. Nesse caso, a diretora do Museu Nacional de Messina, Maria Accascina, obedeceu a "uma antiga tradição do pintor e cenógrafo, G. Morici, de comprovada habilidade". ACCASCINA. M. Museo Nazionale di Messina. Ibid. p. 405. 
Morello, excetuando os casos precedentes e pouquíssimos mais, essa prática na Itália foi uma novidade da "museografia do pós-guerra"24.

Pouco antes dessa revolução museográfica se consolidar, Lina Bo e Pietro Maria Bardi partem recém-casados de Roma ao Brasil. Era a tabula rasa dos Bardi.

\section{Primeira célula ${ }^{25}$}

Lina e Pietro passam a lua-de-mel no Rio de Janeiro, onde expõem e vendem obras de arte ${ }^{26}$. Lá travam contato com Assis Chateaubriand, que os convida a criar uma "galeria de arte antiga e moderna", "uma das maiores do mundo", "um museu igual ao Louvre", mas na cidade onde havia café, indústrias e dinheiro: São Paulo ${ }^{27}$. Bardi, por seu lado, convence Chateaubriand a optar pela denominação "Museu de Arte", não galeria, argumentando que os adjetivos "antiga" e "moderna" eram desnecessários; arte era apenas arte ${ }^{28}$. Havia uma pequeníssima coleção, que Bardi e Chateaubriand engrossariam em breve, em quantidade e qualidade, aproveitando a bonança paulista e a bancarrota européia do pós-guerra. Lina cuidaria da arquitetura no local que lhe fora oferecido: o segundo pavimento do edifício dos Diários Associados ${ }^{29}$. O prédio fora projetado

${ }^{24}$ Ainda segundo Morello: “A intervenção dos arquitetos implica ... um entrelaçamento entre museografia e restauro. Mas ao mesmo tempo implica uma maneira diversa de entender o museu: nas recepções contemporâneas, não por acaso, as confusões e escorregões entre os dois campos são assaz freqüentes". ("L'intervento degli architetti implica ... un intreccio tra museografia e restauro. Ma nello stesso tempo implica una diversa maniera d'intendere il museo: nelle ricezioni contemporanee, non a caso, le confusioni e gli scivolamenti tra $i$ due campi sono assai frequenti".) O prêmio conferido a Scarpa pelo restauro do palácio Abbatelis, em 1963, foi contestado pelo novo superintendente de monumentos de Palermo, Giusepe Giaccone: "O prêmio nacional concedido ao prof. Scarpa pelo restauro do palácio Abbatelis de Palermo guarda outros méritos que o premiado poderá ostentar, mas não o do restauro". ("Il Premio Nazionale' assegnato al prof. Scarpa per il restauro di Palazそo Abbatelis di Palermo riguarderà altri meriti che il premiato potrà vantare ma non quello del 'restauro".) GIACCONE. G. "Lettera al Direttore". Giornale di Sicília. 29 de março de 1963. Apud Id. Ibid. p. 405.

${ }^{25}$ Ver as dissertações de mestrado que abrangem o período de funcionamento do MASP na rua 7 de abril: SCHINCARIOL. Zuleica. Op. cit. 2000 e MOTTA, Renata Vieira da. O Masp em exposição: mostras periódicas na Sete de Abril. São Paulo: FAU-USP, 2003.

${ }^{26}$ MORAES. Fernando. Op. cit. pp. 476-492.

${ }^{27}$ TENTORI, Francesco. Op. cit. pp. 169, 172.

28 "Desde os primeiros ensaios engajados em "Belvedere" [jornal criado por Bardi em 1929, na Itália], ele [Bardi] sustenta uma tese (que é também a de Ardengo Soffici): não faz sentido dividir a arte com vários epítetos e, menos ainda, em "antiga" e "moderna"; a arte é apenas ela mesma". Ibid. p. 31.

29 Antes dos Diários Associados se mudarem para esse prédio, o Guilherme Guinle, no número 230 da rua 7 de abril, eles ocupavam o edifício Conde Prates, que foi demolido para dar lugar ao Palácio Matarazzo, do arquiteto "de Mussolini” Marcello Piacentini (ver TOGNON, Marcos. Arquitetura 
pelo arquiteto Jacques Pilon e o museu seria, portanto, forçosamente "interno" - o que não deve ter surpreendido Lina. A surpresa foi ver o edifício ainda em construção e saber que ali, no meio do canteiro de obras, o museu se instalaria ${ }^{30}$.

A primeira solução museográfica destacava os quadros da parede, pousados em pequenos braços metálicos presos a tubos de alumínio que se fixavam entre o piso e o teto ${ }^{31}$. Um sistema engenhoso, que impressionava pelo efeito e novidade e evitava, segundo a arquiteta, que as paredes úmidas da construção atingissem as telas. Na Itália, uma proposta parecida já havia sido realizada: a de Franco Albini, na galeria Brera de Milão, em 194132. No MASP, porém, o sistema era aplicado a um acervo permanente de arte antiga, e não para uma mostra temporária de um artista contemporâneo, como a que fizera Albini. É claro que não havia aqui a resistência que havia na Itália - embora Bardi sempre lembrasse as dificuldades impostas pelo museu rival, o MAM (evidentemente de outra natureza ${ }^{33}$ ). Em todo caso, o projeto de Albini foi exemplar a outras experiências museográficas:

O sistema de Franco Albini para a mostra de Scipione em Brera (1941) ... constitui em primeiro lugar uma matriz de aproximação ao espaço expositivo, reaparecendo praticamente inalterado em soluções para salas de mostras temporárias e didáticas - seja no Palazzo Bianco ou no Palazzo Rosso [figs. 89 e 90] [ambos de Albini, em Gênova, realizados respectivamente em 1950-51 e 1953-61]. Do mesmo modo, a apresentação de quadros sem molduras, isolados, sobre tubos, nas salas do seu primeiro museu genovês, já havia sido experimentada desde 1938 pelo próprio Albini no mobiliário de sua casa ${ }^{34}$.

italiana no Brasil. A obra de Marcello Piacentini. Editora da Unicamp: Campinas, 1999). Os fatos que levaram ao "despejo" dos Diários pelo conde Matarazzo e à construção do Guilherme Guinle estão em MORAES. Fernando. Op. cit. pp. 347-351.

30 "Em '47, quando começamos nossa aventura com o Museu, naquele andar isolado do prédio ainda em construção dos 'Diários Associados', sem elevador, com o piso repleto de caixas de cal para absorver a umidade das paredes recém rebocadas, com meios técnicos cuja precariedade lembrava a panela e o 'jeito' de fazer fôgo dos bandeirantes...” BARDI, Pietro Maria. "20 anos do Museu de Arte de São Paulo". Op. cit. p. 16.

${ }^{31}$ SCHINCARIOL, Zuleica. Op. cit. p. 57.

32 MULAZZANI. Marco. Id. Ibid. p. 64.

33 “.... em '47 encontramos uma situação bem complexa e subrepticiamente - sejamos francos - hostil e perplexa face tal iniciativa. Parecia que todo mundo tivesse pensado em criar, antes, um museu de arte quando as intenções nem tinham sido formuladas a não ser no verso de um cardápio como às vêzes acontece, depois de um jantar, esboçando um plano que será desenvolvido. Historiadores, posteriormente, elucidaram que de fato existia um plano cardapial, mas que foi esquecido numa mesa do restaurante 'Gigetto”'. BARDI, Pietro Maria. “20 anos...” Op. cit. p. 16.

34 "L'allestimento di Franco Albini della mostra di Scipione a Brera (1941) ... costituisce una matrice innanzitutto per l'approccio allo spazio espositivo; poi, anche per le soluzioni ostensive che ritorneranno, pressoché identiche, nelle sale delle mostre temporanee e didattiche sai a Palazzo Bianco sai a Palazzo Rosso; così come la presentazione dei quadri, scorniciati e isolati su montanti tubolari in 
Ineditismos à parte, o que importa é a qualidade do espaço. No primeiro MASP da rua 7 de abril, a área total chegava a quase $1000 \mathrm{~m}^{2}$, os quadros seguiam-se lado a lado, apoiados nos tubos metálicos, sugerindo um percurso contínuo e permitindo ao mesmo tempo que o olhar "vazasse" a obra, graças à ausência de paredes, ampliando o ambiente. Às vezes, atrás dos quadros, havia cortinas de algodão $\mathrm{cru}^{35}$ ou superfícies lisas em tons claros e neutros (como muitos museus na Europa já vinham fazendo desde os anos 3036). Quando os quadros exibiam o verso, colocavam-se paramentos escuros, para não transparecerem os chassis e fundos de tela. No piso, havia tacos de madeira. O forro era composto por placas removíveis e iluminação fluorescente embutida, com difusores translúcidos ${ }^{37}$. A luz fria podia distorcer as $\operatorname{cores}^{38}$, mas sua distribuição era homogênea e acompanhava em grande parte o percurso das obras. Embora houvesse grandes pilares, às vezes bem próximos uns dos outros, temos a impressão, pelas fotos, de que eles não atrapalhavam: ao contrário, parecem marcar o ambiente e servir como pontos de referência e fundo. Surpreende o posicionamento dos quadros, os arranjos cuidadosamente equilibrados, dosando cheios e vazios, dimensões e contornos, considerando o significado de cada obra em si e também em relação às vizinhas: uma aula de museologia e museografia.

Não havia luz natural: as janelas eram vedadas pelas cortinas de algodão, que, além de servirem como fundo, auxiliavam no equilíbrio das condições ambientais, já que não havia ar condicionado. Outra novidade eram as folhagens. Lina se encantara pela flora do Brasil e espalhou-a pelo museu: elementos vivos em um museu vivo ${ }^{39}$. Mas um ambiente com obras de arte antigas e delicadas, demandando controle de umidade e proteção contra insetos e microorganismos, infelizmente não pode conviver com vegetações ${ }^{40}$. Assim, as plantas foram logo retiradas.

mezzo alle sale del primo dei suoi musei genovesi, viene sperimentata sin dal 1938 dall'architetto milanese nell'arredo della propria casa". MULAZZANI. Marco. Id. Ibid. p. 64.

35 SCHINCARIOL, Zuleica. Op. cit. p. 57.

${ }^{36}$ MORELLO, Paolo. Op. cit. p. 403.

${ }^{37} \mathrm{O}$ uso de lâmpadas fluorescentes era uma novidade cada vez mais comum aos museus da época (ver, por exemplo, a sala dos Primitivos Flamengos no Palazzo Bianco, de Franco Albini). Não havia ainda lâmpadas frias com boa reprodução de cores.

${ }^{38}$ É interessante notar que a luz branca também determinava novas condições de percepção das obras. MORELLO, Paolo. Op. cit. p. 403.

39 As vegetações estão indicadas nos desenhos de Lina como "albero vero". SCHINCARIOL, Zuleica. Op. cit. p. 56 (na legenda).

${ }^{40}$ Ibid. p. 61 (na legenda). 
A museografia não se restringiu apenas a um tipo de suporte. Havia painéis específicos para exposições temporárias, utilizando lâminas de vidro e tubos de alumínio. As peças de junção eram de cobre, patente do engenheiro Santopaolo41. A primeira mostra didática chamava-se "O Panorama da História da Arte", composta por ilustrações com exemplos de pintura, escultura e arquitetura de todos os tempos e lugares ${ }^{42}$. Devido aos limites técnicos e orçamentários, os textos eram inicialmente manuscritos; depois, foram datilografados em uma máquina de escrever importada, com tipos grandes e adaptada aos padrões ortográficos da língua portuguesa. A mostra apresentava informações abundantes, "parecendo querer suprir rapidamente a carência bibliográfica". As mostras seguintes foram "mais sintéticas, visualmente mais leves" e atentas "à legibilidade", sem perderem "de vista o conjunto dos problemas a serem abordados" 43.

Entre os ambientes expositivos havia um auditório de 150 lugares, com piso acarpetado e forro curvo, suspenso pela laje de concreto flutuando como os quadros -, envolto por cortinas de algodão ${ }^{44}$. O ambiente era de extrema leveza e poderia ser totalmente aberto e transformado em uma confortável sala de leitura (como Lina chegou a esboçar), graças a delicadas cadeiras projetadas pela arquiteta, leves e dobráveis, em madeira e couro. Por outro lado, não havia isolamento acústico.

Complementando as exposições, existiam duas grandes vitrines, também desenhadas por Lina para guardar cerâmicas, esculturas e outros objetos $^{45}$.

De modo geral, a exposição das peças do museu era cronológica, seguindo um percurso traçado a partir de sua entrada, no segundo andar do edifício ${ }^{46}$.

O MASP inseria-se conscientemente na linha internacional das instituições "dinâmicas" e "pedagógicas", representando um "museu vivo" em oposição aos "asilos" e "cemitérios" das obras de arte" 4 . Nos EUA, ainda nos anos 1930, o debate sobre arte e educação já havia sido

\footnotetext{
41 "Museu de Arte". Habitat, no. 1, São Paulo, out./dez. 1950, p. 43.

42 SCHINCARIOL, Zuleica. Op. cit. p. 65.

43 "Ensinar a ver e aprender". Diário de S. Paulo. Suplemento Museu de Arte. São Paulo, 9 de julho de 1950, p. 5. Apud SCHINCARIOL, Zuleica. Op. cit. p. 65.

${ }^{44}$ Id. Ibid.

${ }^{45}$ Id. Ibid.

${ }^{46}$ Id. Ibid p. 56.

${ }^{47}$ MORELLO, Paolo. Op. cit. p. 408.
} 
revolucionário, tachado de extremista e se tornado conservador ${ }^{48}$. Contudo, a idéia do living museum e do "pragmatismo americano" (nas obras de John Dewey, Roger Fry, Herbert Read e Frederick Antal) continuaram estimulantes por muitos anos. Giulio Carlo Argan publicaria em 1949 Il Museo come scuola ("pois se a arte é educação, o museu deverá ser escola" ${ }^{49}$ ) e Licisco Magagnato afirmaria, em 1953, que o museu deveria "ser acima de tudo dinâmico":

Atualmente, esquematizando, poderíamos reduzir a três as funções essenciais do museu alvorecido: que se não é contemporaneamente instituto de educação e estudo, centro de conservação e restauro, monumento turisticamente eficiente e equipado, falha em suas tarefas e não compete atuar em nenhuma dessas funções ... Um museu moderno organiza mostras, espetáculos cinematográficos; conferências e guias didáticos; publica livros, documentários, diapositivos e fotografias; executa restauros e promove a atividade artística; tem uma vasta rede de associados e mantenedores privados e realiza uma ativa propaganda, com a mentalidade de uma verdadeira e própria empresa econômica e turística ${ }^{50}$.

\section{Expansão}

O modelo norte-americano inspirou as ações de inúmeros museus em todo o mundo. Não foi diferente com o MASP, que se pautou por ser uma instituição pedagógica dinâmica e filantrópica ${ }^{51}$, de iniciativa empresarial progressista e disciplinada, promovendo serviços sociais e "obras do interesse do povo" ${ }^{52}$. Chateaubriand apreciava imensamente essas idéias, às quais Nelson Rockefeller se referiu na inauguração das novas instalações do MASP, em 1950. O empresário e presidente do MoMA lembrou "as origens comuns" das instituições, seus "mesmos ideais políticos e

\footnotetext{
${ }^{48}$ Id. Ibid.

${ }^{49}$ ARGAN. Giulio Carlo. "Il museo come scuola". Comunità, III, 3, maio/jun. 1949, pp. 64-66. Id. Ibid.

50 "Oggidi, schematizzando, potremmo ridurre a tre le funzioni essenziali del museo aggiornato: che, se non è contemporaneamente istituto di educazione e di studio, centro di conservazione e restauro, monumento turisticamente efficiente ed attrezzato, fallisce ai suoi compiti e non riesce ad attuare nessuna di quelle sue funzioni ... Un moderno museo organizza mostre, spetacoli cinematografici; conferenze e gite didattiche; pubblica libri, documentari, diapositive e fotografie; cura restauri e promuove l'attivitá artística; ha una vasta rete di associati e di sotenitori privati, e svolge um'attiva propaganda con la mentalità di una vera e propria impresa economica e turistica". MAGAGNATO. Licisco. "Il museo attivo". Comunità, VII, 17 de fevereiro de 1953, pp. 56-62. Id. Ibid.

51 "Os Estados Unidos da América se acham decisivamente na vanguarda, com grande vantagem, na concepção moderna e no desenvolvimento vivo de tôdas as iniciativas museológicas que tendem a fazer dos museus um instrumento de educação pública". "Os museus vivos nos Estados Unidos". Habitat, nº. 8, São Paulo, 1951, p. 12.

${ }^{52}$ ROCKEFELLER, Nelson A. "Cidadelas da Civilização". Habitat, n’. 1, São Paulo, out./dez. 1950, pp. 18-19. Apud SCHINCARIOL, Zuleica. Op. cit. p. 51.
} 
econômicos, reforçando as relações entre "países irmãos", já consolidadas desde a Segunda Guerra, agora em direção à Guerra Fria" 53.

Ainda em 1950, Lina Bo Bardi publicou seu artigo Função social dos museus ${ }^{54}$, no primeiro número de sua revista Habitat. Nele afirmam-se os mesmos pressupostos do living museum, atuando para "formar uma mentalidade para a compreensão de arte", contra as atividades de um "mausoléu intelectual", preocupado apenas com a conservação do acervo. Dois anos depois, Lina acrescentaria que o museu deveria vivificar e rejuvenescer, "abrir suas portas, deixar entrar o ar puro, a luz nova" 55.

Acompanhando a expansão do acervo e atividades (sobretudo didáticas), o MASP passa a ocupar mais um andar do edifício, além de duas salas da sobreloja para abrigar a reserva técnica ${ }^{56}$ - totalizando quase 2300 $\mathrm{m}^{2}$. No primeiro pavimento situavam-se então os setores administrativo e educativo $^{57}$, com uma pequena sala para exposições temporárias (disponível principalmente a artistas brasileiros jovens ${ }^{58}$ ) e dois auditórios - além do primeiro, construiu-se outro maior, fechado e com melhor isolamento acústico. No pavimento superior, ficavam a pinacoteca e as grandes exposições temporárias. O jornalista Geraldo Ferraz qualificou a adaptação como "uma realização racional arquitetônica que revela, na sua concepção, uma notável capacidade de tornar elástico o espaço rígido ocupado, e assim subordiná-lo aos vários departamentos necessários ao Museu de Arte" 59. O MASP estava mais equipado, com ateliê de gravuras, laboratório de fotografia e uma substancial biblioteca de arte emprestada por Bardi, com volumes raros como o Cours d'Architecture, de François Blondel, publicado em $1698^{60}$. A biblioteca ficava dentro da sala de Bardi, aberta a consultas, o que demonstra sua importância não apenas como apoio ao diretor, como também ao caráter acessível e educativo do MASP.

\footnotetext{
53 SCHINCARIOL, Zuleica. Id. Ibid.

${ }^{54}$ BARDI, Lina Bo. "Função social dos museus". Habitat, no. 1, Op. cit. p. 17. Apud SCHINCARIOL, Zuleica. Op. cit. p. 51.

${ }_{55}$ BARDI, Lina Bo. "O que é um museu”. Habitat, no. 9, São Paulo, 1952, p. 52. Apud Id. Ibid.

${ }^{56}$ Cf. depoimento de Luiz Hossaka. Id. Ibid p. 79.

${ }^{57}$ No setor educativo ficavam o ateliê de gravuras e os cursos para crianças. Pouco tempo depois, seriam incorporados mais dois andares do prédio ao MASP, "especialmente para as escolas, o quarto e o décimo quinto, este ocupado pelos setores de música e dança; os cursos funcionavam das 8:00 às 23:00 nesse período". Id. Ibid p. 83.

${ }^{58}$ Id. Ibid.

${ }^{59}$ FERRAZ, Geraldo. "As Novas Instalações do Museu de Arte de São Paulo”. Diário de Notícias. São Paulo, 2 de junho de 1950. Apud Id. Ibid.

${ }^{60}$ TENTORI, Francesco. Op. cit. p. 148.
} 
Houve uma nítida continuidade com a proposta anterior, além de algumas mudanças substanciais, que Lina Bo Bardi, em seu artigo, explicou:

O critério que informou a arquitetura interna do Museu restringiu-se a soluções de 'flexibilidade', à possibilidade de transformação do ambiente, unida à estrita economia que é própria de nosso tempo. Abandonaram-se os requintes evocativos e os contornos, e as obras de arte antiga não se acham expostas sobre veludo, como o aconselham ainda hoje muitos especialistas em museologia, ou sobre tecidos da época, mas colocadas corajosamente sobre fundo neutro. Assim também as obras modernas, em uma estandardização, foram situadas de tal maneira que não colocam em relevo a elas, antes que o observador lhes ponha a vista. Não dizem, portanto, 'deves admirar, é Rembrandt', mas deixam ao espectador a observação pura e desprevenida, guiada apenas pela legenda, descritiva de um ponto de vista que elimina a exaltação para ser criticamente rigorosa. Também as molduras foram eliminadas (quando não eram autênticas da época) e substituídas por um filete neutro. Desta maneira as obras de arte antigas acabaram por se localizar numa nova vida, ao lado das modernas, no sentido de virem a fazer parte na vida de hoje, o quanto possível ${ }^{61}$.

As obras antigas eram consideradas cada vez mais equivalentes às modernas ${ }^{62}$. Na mesma revista, a reprodução das imagens do acervo reforça essa postura: a diagramação as misturava, sem seguir os tradicionais critérios cronológicos ou regionais. A disposição das obras no museu, porém, continuava a acompanhá-los, às vezes incorporando temas específicos, como retratos, ou cruzando percursos de forma estimulante ${ }^{63}$. Delineava-se um conflito entre o desejado e o concretizado: embora Lina e Bardi viessem de uma mesma cultura, as formações e idades eram diferentes (a arquiteta com cerca de 35 anos e o diretor com 50). A experiência de Bardi assegurava que as obras contemporâneas precisavam do "teste do tempo" ${ }^{4}$, enquanto para Lina ainda havia muito a descobrir. De todo modo, os entendimentos entre ambos resultavam mais que satisfatórios - assim como à maioria do público e crítica ${ }^{65}$ : o acervo respirava amplamente no novo pavimento. O espaço de exposição crescera e o sistema de suportes pôde transformar-se. A exemplo de vários projetos elaborados por Mies van der Rohe e seus discípulos, nos anos 40, Lina desenhou painéis retangulares soltos do piso, pendurados por fios, criando

\footnotetext{
${ }^{61}$ BARDI, Lina Bo. "Função social dos museus". Apud Id. Ibid. p. 89.

${ }^{62}$ Id. Ibid p. 92.

${ }^{63}$ Id. Ibid.

${ }^{64}$ BARDI, P. M. The Arts in Brazil: A New Museum at São Paulo. Milão: Del Milione, 1956, pp. 96, 98. Id. Ibid p. 27.

${ }^{65}$ Apesar dos elogios ao MASP serem publicados nos periódicos de Chateaubriand e dos Bardi, não parecem distorcer a reação geral dos visitantes a um espaço completamente novo e deslumbrante, que as fotos de ótima qualidade nos arquivos do MASP e do Instituto Lina Bo e Pietro Maria Bardi nos informam.
} 
um fundo aos quadros e aumentando substancialmente a área de circulação. Renovou-se a idéia de suspensão: ao invés dos quadros isolados, eram os painéis que flanavam. Talvez por segurança os painéis não foram pendurados ao teto: interligavam-se por meio de cabos e fixavam-se a tubos de alumínio apoiados no chão.

Os painéis eram compostos por placas de madeira, variando o revestimento em cores primárias: "o branco, o preto, tonalidades de cinza, pontualmente o vermelho e o azul saturados" ${ }^{66}$. O piso foi revestido com tacos de madeira, maiores que os do primeiro pavimento e assentados com outra disposição, características coerentes à escala do novo salão. $\mathrm{O}$ forro também possuía outra modulação e aletas metálicas para minimizar o ofuscamento da luz direta, reduzindo os reflexos. Dessa vez buscou-se uma aproximação ao "espectro da luz solar, mesclando lâmpadas fluorescentes com emissões dominantes na faixa do vermelho e do azul" ${ }^{67}$. As lâmpadas fixavam-se contra um fundo de algodão, para corrigir, homogeneizar e aproveitar melhor o rendimento da luz. O uso de iluminação fluorescente em muitos museus continuava em alta, mas as publicações já alertavam para os efeitos danosos de seus raios ultravioletas à conservação das obras de $\operatorname{arte}^{68}$.

As esculturas foram localizadas próximas às paredes, às vezes juntas aos pilares, que participavam muito menos do ambiente, se comparados à proposta de 1947. Havia anteparos como fundo para as esculturas, na maioria negros (sobretudo às esculturas de mármore branco, como a Deusa Higéia e a Diana Adormecida ${ }^{69}$ ), às vezes com leve ondulação, como que protegendo a obra de arte, realçando seus volumes e alongando o fundo aos vários ângulos de visão. Os pedestais (os mesmos da instalação de 1947) variavam nas dimensões e cores, mas geralmente eram cubos ou paralelepípedos brancos, cujas massas articulavam-se vivamente. A distribuição de formas e volumes configuravam quase um suprematismo tridimensional - ou uma feliz evocação aos móbiles e estábiles de Calder (artista que expusera poucos anos antes no MASP). A escultura Deus Pai, de Girolamo Santacroce, apoiava-se sobre uma base prismática como

${ }^{66}$ Id. Ibid p. 92.

${ }^{67}$ Id. Ibid pp. 92-93.

68 "Extreme ultra-violet radiation from tubular fluorescent lamps and its effect on museum lightning". Museum vol. V. Paris: Unesco, 1952, reimpressão 1973, Kraus Reprint (Lieschtenstein, Alemanha). Ibid p. 93.

${ }^{69}$ Id. Ibid p. 92. 
esmagando-a, acentuando a tensão da peça. Um pedestal semelhante foi utilizado na escultura egípcia da XXa dinastia, mas com efeitos diversos (sobretudo quando contraposto a uma grande veneziana fixa branca).

As esculturas foram expostas de modo extremamente cuidadoso, superando a configuração de 1947. Os pedestais evocavam a estrutura do prédio, como se fossem maquetes dos pilares, integrando arquitetura e museografia (tanto os pedestais das esculturas maiores como os que ficavam na nova Vitrine das Formas, também desenhada pela arquiteta). Porém, a utilização dos pilares como elementos museográficos é nitidamente menor nessa proposta que na anterior, ou seja, os pilares correspondem quase que estritamente à sua função estrutural e arquitetônica (os próprios painéis são estabilizados por meio de cabos presos a eles). Não que os pilares fossem dispensáveis à museografia, pois muitas esculturas utilizavam-nos como fundo. Mas provavelmente a ampliação do espaço encantou tanto a arquiteta que ela preferiu concentrar a reforma nesse aspecto. Os pilares passaram a incomodá-la cada vez mais como obstáculos à livre disposição das obras de arte ${ }^{70}$ - à arquitetura que recorrentemente preza pelos "espaços generosos". Há um desenho de Lina nos quais os pilares são "camuflados" por painéis serpenteantes, onde o envolvimento da estrutura com a museografia seria maior, mas ainda visivelmente incômoda. No mesmo número de Habitat em que se divulgava a ampliação do MASP foi publicada a imagem de um amplo salão para esculturas do século XIX, com estrutura metálica e cobertura de vidro. O número seguinte de Habitat publicou uma nota de esclarecimento:

Vários leitores nos escreveram perguntando ao que se referia um clichê representando uma galeria de estátuas, que acompanhava o artigo 'Função Social dos Museus'. Trata-se dum dos salões da Exposição Universal de Paris de 1900. O leitor que achou esta sala bonita tem razão; não tem razão, pelo contrário, aquele que a achou fria. A sala deve ser interpretada como expressão da época em que foi construída ${ }^{71}$.

A arquiteta alimentava cada vez mais o interesse por amplas áreas livres: plantava a idéia do edifício do MASP72. Enquanto a semente não germinasse, as obras de arte seriam distribuídas à melhor fruição individual

\footnotetext{
${ }^{70}$ Id. Ibid p. 88.

${ }^{71}$ Habitat, n' ${ }^{\circ}$. 2, São Paulo, jan./mar. 1951, p. 17. Id. Ibid p. 88.

72 "Em sua conferência sobre arte e técnica, dada na Bahia justamente em 1958, ano em que os primeiros estudos para o Masp já estariam em curso, Lina cita o Crystal Palace de Londres e a Galerie de Machine em Paris, dois exemplos de construções industriais que the permitem afirmar que "foi sob o útil que se construiu o belo"”. OLIVEIRA, Olivia. Op. cit. p. 280.
} 
e conjunta no espaço da 7 de abril. Nesse ponto, o MASP aproximava-se às experiências contemporâneas do museu interno italiano, que, porém, trabalhavam uma difícil equação: equilibrar patrimônios artísticos e arquitetônicos consagrados. Até aquele momento, o MASP desenvolveu uma museografia estimulante e ao mesmo tempo respeitosa ao acervo permanente de obras de arte, além de diversificada e engenhosa. Logo depois, o museu brasileiro caminhará em outro sentido: a riqueza de suportes diminuirá; a individualidade das obras de arte será mais e mais pulverizada, até "democratizarem-se" num ambiente homogêneo: a pinacoteca na avenida Paulista, inaugurada em 1968, onde as pinturas serão expostas nos cavaletes de cristal, painéis de vidro apoiados em cubos de concreto aparente, um suporte "universal" aos quadros. Nos museus italianos, ao contrário, as obras receberam atenção individual, ganhando suportes, paredes e iluminações pensadas às suas especificidades; às vezes um ambiente inteiro e aparatos técnicos dedicados exclusivamente a uma única peça.

\section{Vertentes}

A museografia italiana do pós-guerra possui grande diversidade de exemplares dificilmente classificáveis, o que não impediu os pesquisadores Ezio Bonfanti e Marco Porta de dividirem-na em dois modelos, representados pela galeria do Palazzo Bianco, de Franco Albini, e o Museu Correr, de Carlo Scarpa ${ }^{73}$. O primeiro seria marcado por uma "programática neutralidade", "rigor formal, controle do desenho, racionalidade e frieza". O segundo seria "apaixonado", voltado "ao envolvimento e participação". Haveria ainda uma terceira linha, mais radical, prosseguindo de certo modo a "veia artesanal e populista" de Scarpa, representada por um projeto do estúdio BBPR, o castelo Sforzesco.

A proposta do BBPR mostra-se "consciente da crise dos valores racionalistas", opondo-se ao "museu-coleção", ao "museu filológico e neutro", buscando constituir um "compêndio da história civil de uma população, um museu-monumento e o lugar onde se estabelece e adensa o valor civil de uma cidade", uma instituição que "não chega a ser um museu ativo na acepção deweyana ... mas tampouco é ainda um museu tradicional"

${ }^{73}$ BONFANTI, Ezio. PORTA, Marco. Città, museo e architettura. I Bbpr e la cultura architettonica italiana. Milão, 1973, p. 153. Apud MORELLO, Paolo. Op. cit. p. 395-396. 
74. Bonfanti e Porta acrescentam que o modelo "neutro", "frio" e "racional" do Palazzo Bianco de Albini não deixou seguidores. Podemos imaginar o MASP relacionado à vertente de Albini, mas claramente levado a um extremo maior do que o BBPR levara a vertente de Scarpa, sobretudo de modo bastante diverso.

Se existe um ponto de contato entre o MASP e a museografia italiana do pós-guerra - além dos suportes -, este consiste em uma preocupação "cívica", principalmente em comparação ao castelo Sforzesco. No mais, tudo é diferente, a começar pelos edifícios (um novo, o outro adaptado), terminando na organização das obras e na variedade dos suportes, nos quais as aplicações museológicas são extremamente distintas. Em síntese, no museu brasileiro os suportes e sua organização espacial possuem apenas uma configuração, independente da variedade das obras de arte, que se adequam à museografia de um imenso salão. Nos museus italianos ocorre o contrário: em diversos níveis, os suportes adequam-se às obras de arte, em sub-salas ou ambientes temáticos, chegando a existir uma só sala para apenas uma obra de arte, com suportes e aparatos específicos a ela.

Tomemos um exemplo italiano: a proposta para o museu Correr, ao qual Scarpa desenhou uma sala específica para a Deposição de Cristo de Antonello da Messina [fig. 1a]. A atmosfera criada pelo arquiteto emana do próprio quadro: a textura do travertino alude à pele do Cristo, à ferida aberta pela estocada de lança; os suportes metálicos são tão delicados quanto às asas dos anjos, em seu cuidadoso trato ao corpo do Cristo; a sombra do quadro no travertino "reproduz" as sombras pintadas por Antonelo. Suporte e ambiente resultam, portanto, da atenção concentrada em uma única obra de arte. O cavalete de cristal, pelo contrário, é único para pinturas muito diversas. E se ele proporciona efeitos sugestivos e espirituosos ao interagir quadros e espectadores - como mostra a foto "unindo" um busto pintado por Modigliani ao corpo de uma espectadora [fig. 1b] -, tais efeitos são possíveis apenas a partir de pouquíssimas obras do acervo. Sua museografia, afinal, prioriza o conjunto, menosprezando o particular.

As atitudes de Scarpa e Lina são completamente distintas, assim como suas intenções. Sem dúvida Lina conhecia muito bem o acervo do MASP. Porém, além de menosprezar suas particularidades, a arquiteta

\footnotetext{
${ }^{74}$ Ibid. p. 396.
} 
passou também a menosprezar as obras "clássicas" e autorais, afeiçoandose mais e mais às "primitivistas" e anônimas, aos ex-votos, redes, carros-deboi e mamulengos: é o que demonstra a grande mostra realizada por ela e Bardi em 1969, A mão do povo brasileiro [fig. 2]. Em outras palavras, embora o acervo do MASP seja em muitos aspectos incomparável às peças dessa mostra, está claro (mesmo em fotografias) que o empenho da arquiteta em A mão do povo brasileiro foi superior, assim como seus resultados: a variedade de arranjos e o cuidado com a disposição dos objetos evidenciam a alta qualidade expográfica. Em conseqüência disso a mostra tornou-se uma importante referência na área, mas também (e sobretudo) por sua interação excepcional com o público ${ }^{75}$ (pois, para conseguir os objetos, várias chamadas foram publicadas em jornais ${ }^{76}$ ). A exposição contou com peças da Universidade do Ceará, do Museu do Folclore de São Paulo e de coleções particulares ${ }^{77}$, integrando coerentemente museologia, museografia e $\operatorname{arquitetura}^{78}$.

Surgiram várias possibilidades para levar a exposição a outros países ${ }^{79}$. Mas como Lina afastou-se do MASP, a experiência foi única. Depois disso, Bardi promoveu inúmeras mostras temporárias notáveis, talvez nenhuma tão fantástica quanto $A$ mão do povo brasileiro. De todo modo, as museografias temporárias no MASP sempre foram necessariamente adaptáveis às obras de arte, enquanto no salão da pinacoteca praticamente congelou-se um lay out - um dos alvos de ataque à museografia dos cavaletes de cristal.

75 Inúmeras cartas e recibos de empréstimos (de maio de 1969) e de devolução aos proprietários (de novembro e dezembro de 1969) demonstram o trabalho e a dedicação do museu e colaboradores à exposição. Biblioteca e Centro de Documentação do MASP (doravante BCDMASP).

${ }^{76}$ Alguns jornais que divulgaram o apelo: CITY-News. São Paulo, 20 de abril de 1969. O Estado de S. Paulo. São Paulo, 20 de abril de 1969.

${ }^{77}$ Jornal O Globo. Rio de Janeiro, 30 de junho de 1969. BCDMASP.

78 “"Mão do povo brasileiro' no Museu 'Assis Chateaubriand”'. Diário de São Paulo. São Paulo, 19 de junho de $1969,1^{\circ}$ caderno, p. 11. BCDMASP.

${ }^{79}$ Carta datilografada de P. M. Bardi e L. S. Hossaka (secretário) ao sr. Emilio Ambasa, Curator of Design do MoMA-NY, 15 de agosto de 1969 (em resposta à solicitação do mesmo; trata-se do envio de 13 fotografias da exposição $A$ mão do povo brasileiro ao Smithsonian Institute). BCDMASP. Carta datilografada de P. M. Bardi ao Victoria and Albert Museum, 13 de novembro de 1969 (verificando a possibilidade de apresentar a exposição $A$ mão do povo brasileiro em Londres). BCDMASP. "Gomes Sicre, diretor da secção de artes visuais da 'Pan american Union' de Washington, vem a São Paulo a fim de levar a expo folclorica ‘A mão do povo brasileiro' para a capital norte-americana." Folba de São Paulo. São Paulo, 25 de agosto de 1970, p. 30. BCDMASP. 

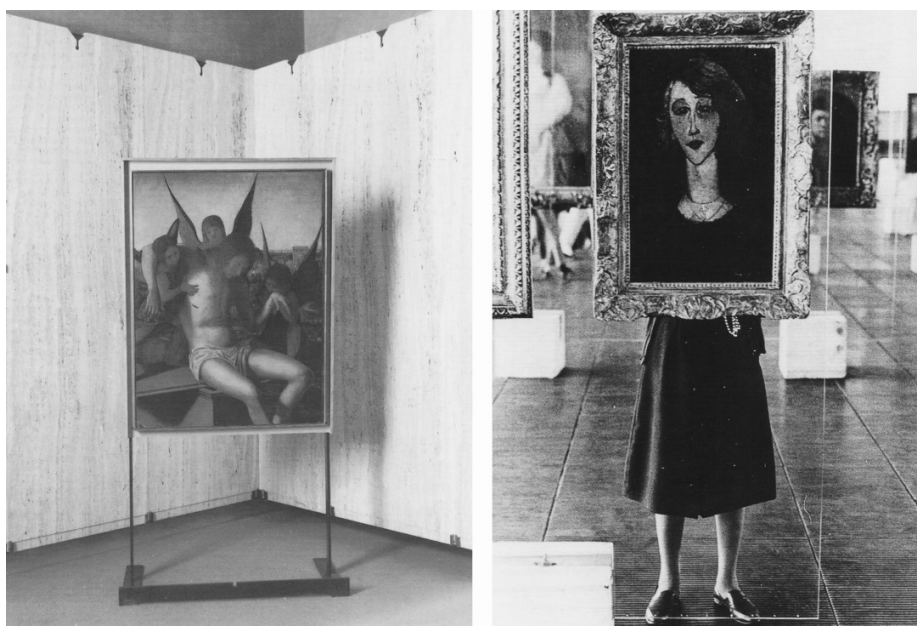

Fig. 1a (esq.): Carlo Scarpa, Museu Correr, sala dedicada à Deposição de Cristo de Antonello da Messina (talvez a principal obra do museu; notar a simplicidade formal do suporte, colocado em diagonal contra um fundo opaco em travertino, delicadamente suspenso por uma estrutura metálica, "alterando as dimensões da sala e sacrificando sem exitações uma janela" - a exemplo da solução de Albini para a sala do Pálio de da Margherita, no Palazzo Bianco), seção da quadreria, Veneza, 1957-60 (fonte: HUBER, Antonella. Op. cit. p. 114, 118-119).

Fig. 1b (dir.): Exposição permanente do MASP no $2^{\circ}$ andar, com os cavaletes de cristal (fonte: FERRAZ, Marcelo Carvalho (org.) Museu de Arte de São Paulo. São Paulo: Insituto Lina Bo e P.M. Bardi / Blau, 1997, s/p.).
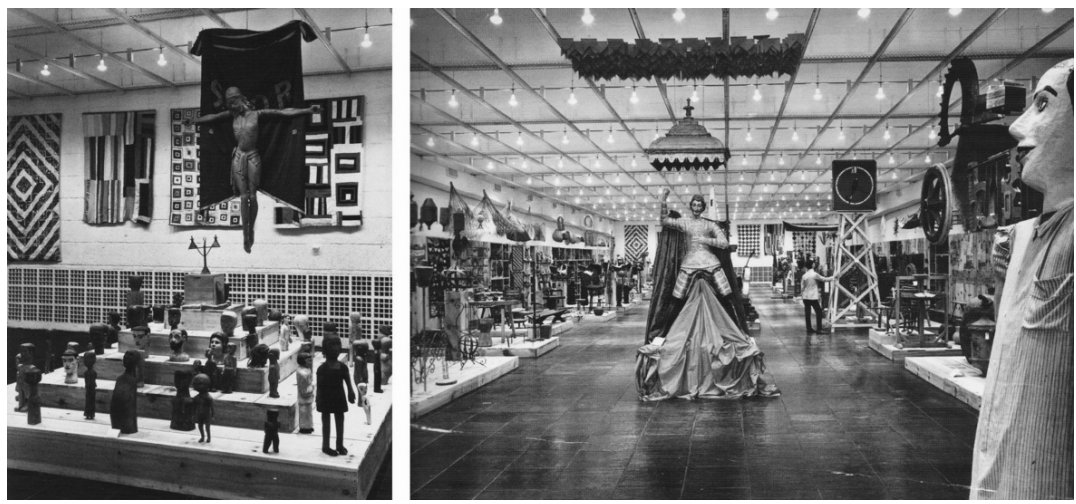

Fig. 2: Exposição $A$ mão povo brasileiro, $1^{\circ}$ andar, 1969 (fonte: FERRAZ, Marcelo Carvalho (org.) Lina Bo Bardi. São Paulo: Insituto Lina Bo e P.M. Bardi, 1993). 